\title{
COMPETÊNCIA INTERACIONAL: CRITÉRIO PARA AVALIAÇÃO DA PRODUÇÃO ORAL EM LÍNGUA ADICIONAL **
}

\section{INTERACTIONAL COMPETENCE:CRITERION FOR ASSESSING ADDITIONAL LANGUAGE ORAL PRODUCTION}

\section{Marcia Niederauer ${ }^{*}$}

\section{RESUMO}

Este texto aborda um dos critérios adotados na Parte Oral do Certificado de Proficiência em Língua Portuguesa para Estrangeiros (Celpe-Bras): a competência interacional, mais especificamente o uso de estratégias comunicativas. Para tanto, partindo-se de estudos realizados por Fulcher (2003), Luoma (2005) e McNamara (1997), sobre avaliação da produção e compreensão oral em língua adicional, por Young (2000a, 2000b), sobre competência interacional, e por Dörnyei e Scott (1997), sobre estratégias comunicativas, é analisado um dos aspectos que caracterizam, conforme a Ficha de Avaliação da interação face a face utilizada pelo avaliador-observador do Exame, a competência. Com base na análise dos dados e nas discussões empreendidas a partir dos estudos com os quais este texto dialoga, o artigo conclui que a forma como essas estratégias são operacionalizadas na grade de avaliação em questão e as orientações disponibilizadas no Manual do Avaliador do Celpe-Bras e no Guia do Examinando - Versão Eletrônica Simplificada não permitem que se aproveite a capacidade avaliativa que tais recursos interacionais oferecem. Além disso, a análise revelou algumas inconsistências em relação ao que se espera nos diferentes níveis de proficiência em termos de uso e de necessidade de uso de estratégias comunicativas durante a entrevista para avaliação da proficiência oral nesse Exame.

Palavras-chave: avaliação; competência interacional, língua adicional.

\section{ABSTRACT}

This paper discusses one of the criteria adopted in face to face interaction of Celpe-Bras Exam, the interactional competence, more specifically, one of the characteristic of this competence: the use of communication strategies. For this purpose, I analyze the grade scheme of face to face interaction - examiner - (2013 /2), taking into account the studies by Fulcher (2003),

\footnotetext{
* UnB, Brasília (DF), Brasil. marciaefn@gmail.com

** Este artigo é uma versão revisada e atualizada do texto que escrevi para cumprir uma das qualificações fora de área durante meu doutorado no Programa de Pós-Graduação em Linguística Aplicada do Instituto de Estudos da Linguagem da Unicamp. A propósito, expresso minha imensa gratidão à Profa. Dra. Matilde V. Scaramucci, que paciente e sabiamente orientou esse trabalho e gentilmente avaliou o texto final dessa qualificação.
} 
Luoma (2005), and McNamara (1997), about speaking and listening assessment, by Young (2000a, 2000b), about interactional competence, and by Dörnyei and Scott (1997), about communication strategies in additional language. Based on the discussions undertaken from such studies and on the data analysis, this paper concludes that the way these strategies are operationalized in this grade scheme and in the guidelines for providing information to examiners and to candidates of Celpe-Bras do not allow to availing the evaluative capacity that such interactional resources offer. Furthermore, the analysis has shown some inconsistencies concerning to what is expected at different levels of proficiency in terms of need and use of communication strategies during the interview for the assessment of oral proficiency.

Keywords: language assessment; interactional competence; additional language.

\section{INTRODUÇÃO}

Em um exame de proficiência em língua adicional (LA, daqui em diante), os procedimentos, as tarefas e a grade de avaliação têm implicações não só para o desempenho dos examinandos, mas também impactos sociais e políticos que ultrapassam o âmbito individual ou institucional. Isso atribui grande importância a estudos sobre os diferentes itens potencialmente relevantes para avaliações de proficiência.

Diga-se, já de início que, por diversos motivos, exames de proficiência oral em LA são, conforme alerta Fulcher (2003), os menos desenvolvidos. As descrições dos elementos que constituem a produção e a compreensão oral resultantes das inúmeras pesquisas realizadas sobre o tema nos últimos anos parecem ainda não fornecer evidências suficientes que permitam a formulação de instrumentos para avaliação "consistente" da produção oral (FULCHER, 2003). Essa relativa "incipiência" dos conhecimentos sobre o que constitui a produção e compreensão oral em LA tem, assim, implicações diretas para a validade de exames que buscam aferir o desempenho oral de um falante bilíngue ${ }^{1}$. Apesar de acometer todas as dimensões da produção e compreensão oral em LA, é necessário que se saliente que algumas dimensões sofrem mais do que outras em termos de evidências claras para a formulação de um construto. A competência interacional ( $\mathrm{CI}$, daqui em diante) é, sem dúvida, uma delas. Por entender que discutir critérios de avaliação de desempenho oral é, de alguma forma, contribuir para o entendimento dos elementos que formam a

\footnotetext{
1 Note-se, de passagem, que, em função da carga negativa que o termo "falante não nativo" carrega, opto por "falante bilíngue". Ser "não nativo" implica a priori, entre outras coisas, produções linguísticas problemáticas, deficientes, menos aceitáveis e menos legítimas do que as dos "falantes nativos". Para uma discussão crítica e aprofundada sobre o conceito de bilinguismo, ver Maher (2007). Ressalto ainda que chamar o falante não nativo de bilíngue não implica que o falante nativo não possa ser também bilíngue, mas sim que, no contexto analisado, sua língua materna é a língua na qual se dá a comunicação.
} 
interação oral em LA e, consequentemente, para o desenvolvimento de instrumentos para aferir a produção oral é que me proponho a discutir um dos critérios de avaliação adotados na Parte Oral do Exame para a obtenção do Certificado de Proficiência em Língua Portuguesa para Estrangeiros (Celpe-Bras, daqui em diante).

Este artigo estrutura-se da seguinte forma: a seção 2 discute, ainda que de modo bastante breve, questões sobre validação de exames para aferir o desempenho oral. A seção 3 aborda o contexto histórico das avaliações da produção e compreensão oral, que é seguida por uma síntese de alguns estudos dedicados à interação oral em LA. A seção 5 trata da competência interacional enquanto critério para avaliar o desempenho oral no Exame para obtenção do Celpe-Bras, buscando discutir especificamente o uso de estratégias comunicativas, um dos itens que caracterizam essa competência na grade de avaliação da Parte Oral do Exame. A partir de estudos sobre estratégias comunicativas e seu papel na interação entre falantes nativos e bilíngues, analiso a forma como o uso destes recursos interacionais é implementada na Ficha de Avaliação da interação face a face utilizada pelo avaliador-observador. Ao final da seção, buscando operacionalizar as discussões e análises empreendidas no artigo, proponho alterações nessa Ficha no que se refere ao critério competência interacional, de forma a atualizar o foco sob o qual se afere o uso de estratégias comunicativas no desempenho oral nesse Exame. Finalizo o artigo, tecendo considerações gerais sobre o emprego dessas estratégias na avaliação da CI.

\section{EXAMES DE PROFICIÊNCIA ORAL E A TRAJETÓRIA DA VALIDAÇÃO}

As concepções contemporâneas de avaliação, conforme esclarece Chapelle (1999), compreendem a validade como uma questão de argumentar a interpretação e o uso de um teste, por meio de uma série de justificativas lógicas e evidências, incluindo as consequências do teste. Em outros termos, validar um instrumento de avaliação implica: justificar o construto do exame; buscar evidências de que os conteúdos cobrados, os propósitos e os critérios de avaliação do exame estão de acordo com esse construto; considerar o impacto do exame no examinando e naqueles que usam as grades de avaliação (LUOMA, 2005) e contemplar as implicações sociais e políticas desse exame (MCNAMARA, ROEVER, 2006).

Entre os passos descritos por Luoma (2005) como os principais a serem seguidos para a validação ${ }^{2}$ de exames para avaliação do desempenho oral em LA,

\footnotetext{
2 Para uma síntese bastante esclarecedora sobre as concepções contemporâneas de validação, cf. Scaramucci (2009).
} 
menciono, a seguir, apenas aqueles que me pareceram particularmente relevantes à discussão que ora proponho. Um deles diz respeito à clareza na definição do construto ao qual o exame pretende acessar; o outro se refere à validade dos critérios. Em relação ao primeiro passo mencionado, cumpre dizer que

\begin{abstract}
o termo construto refere-se a um construto psicológico, uma conceitualização teórica sobre um aspecto do comportamento humano que não pode ser medida ou observada diretamente. Exemplos de construtos são inteligência, motivação para o rendimento, ansiedade, rendimento, atitude, dominância e compreensão em leitura. Validação de construto é o processo de coleta de evidência para dar apoio ao argumento de que um teste realmente mede o construto psicológico que os elaboradores querem que meça. O objetivo, nesse caso, é determinar o significado dos escores ou notas do teste para garantir que eles signifiquem o que o especialista esperava que significassem (EBEL, FRISBIE, 1991 apud SCARAMUCCI, 2009, p. 32) ${ }^{3}$.
\end{abstract}

Sob esta perspectiva, uma entrevista oral, por exemplo, não é um canal de acesso direto à proficiência oral em LA do examinando, o que significa dizer que avaliar a produção oral em LA implica associá-la a evidências observáveis e passíveis de serem classificadas em pontos ou notas (FULCHER, 2003). Para tanto, fazem-se necessárias concepções claras sobre produção oral e sua constituição, bem como definições inequívocas e operacionais sobre o que se deseja avaliar no desempenho oral do examinando.

A este respeito, Fulcher (2003) assinala que, apesar das várias tentativas de descrição das dimensões da produção e compreensão oral, os fatores que nelas interferem ainda carecem de estudos. Essa evidente falta de "clareza" do que realmente constitui as dimensões orais da língua impede que se definam, de modo substancial, construtos a serem avaliados no desempenho oral em LA. Tudo isso tem implicações óbvias para a validade de exames que buscam avaliar a produção oral e que, repita-se, são os menos desenvolvidos na área de avaliação de LA.

Outro passo crucial para a validação de um exame de proficiência em LA, conforme indicado anteriormente, é a validade dos critérios. Isto é, os critérios, segundo destaca Luoma (2005), devem ser coerentes com o propósito do exame, com a definição do construto. Nesta direção, vale salientar que o Celpe-Bras é um exame que, alinhando-se a perspectivas teóricas que compreendem a linguagem como ação, busca avaliar a proficiência em português a partir do uso da linguagem como prática social. Além disso, cada critério, além de coerente com as tarefas propostas pelo exame, deve ser definido concretamente, de forma que seu emprego

\footnotetext{
3 As traduções das citações retiradas de obras em língua estrangeira são de minha responsabilidade, exceto aquelas já publicadas em língua portuguesa assinaladas nas referências bibliográficas.
} 
seja "praticável". Assim, no momento em que se concebe "competência interacional" como uma das dimensões da produção oral a serem avaliadas, cria-se a demanda por tarefas que permitam que os avaliadores observem o desempenho do examinando nesse critério e também por descrições concretas e operacionais de elementos identificáveis em sua interação oral com o avaliador.

Segundo Fulcher (2003), no começo do século XX, avaliar produção e compreensão oral significava aferir a pronúncia e a acuidade gramatical, em geral a partir de tarefas de leitura em voz alta. Essa metodologia de avaliação, entretanto, não serve para exames que, concebendo a língua como prática social, procuram avaliar a capacidade do examinando em mobilizar conhecimentos e recursos linguísticos e interacionais no uso significativo da LA. Assim, desde os anos 1980, conforme assinala Scaramucci (2000), vários exames de proficiência têm adotado a entrevista como procedimento para a avaliação do desempenho oral, entre eles o Celpe-Bras. Neste procedimento, busca-se gerar evidências que permitam inferir, a partir de uma amostra de desempenho, o nível de proficiência oral de um falante bilíngue.

Assim, no Exame Celpe-Bras, na Parte Oral, a produção e a compreensão $\mathrm{oral}^{4}$ são avaliadas com base no desempenho do examinando em uma interação face a face com um entrevistador. Segundo a versão do Guia do Examinando (2013, p. 11), essa Parte do Exame

constitui-se de uma conversa, com duração de 20 minutos, entre examinando e entrevistador, sobre atividades e interesses do examinando, a partir de tópicos que constam no questionário de inscrição (família, bobbies, profissão, entre outros) e sobre tópicos do cotidiano e de interesse geral (ecologia, educação, esportes, entre outros), com base em três elementos provocadores diferentes (fotos, cartuns, quadrinhos, textos curtos etc.) $[\ldots]$

Espera-se que a interação ocorra de maneira conversacional. A este respeito, Brown (2003) pontua que o estilo desse gênero de entrevistas de proficiência oral é cada vez menos estruturado e cada vez mais conversacional. Isto é, não há um script rígido a ser seguido; os entrevistadores, em geral, recebem guias com sugestões de tópicos a serem abordados. No Celpe-Bras, conforme Furtoso (2011, p. 228),

O entrevistador tem que ser capaz de: alterar a ordem das perguntas, excluir perguntas que já tenham sido respondidas em outras, complementar e/ou reformular perguntas quando necessário, objetivando-se, sempre, manter o fluxo significativo da interação.

4 Cabe destacar que a compreensão oral é avaliada também por meio das tarefas 1 e 2 da Parte Escrita do Exame. 
O Guia do Examinando - Versão Eletrônica Simplificada (2013, p. 7) explicita que, durante essa interação, dois avaliadores atribuem, de forma independente, notas para o desempenho do examinando, sendo que,

enquanto um interage com o examinando e lhe confere uma nota, levando em conta a interação, o outro observa e analisa seu desempenho de forma analítica, utilizando uma grade com seis critérios (compreensão, competência interação [sic.], fluência, adequação lexical e gramatical, pronúncia) com gradações de desempenho específicas para cada nível.

Conforme a citação acima, um dos critérios analisados no desempenho dos examinandos na Parte Oral do Exame é a competência interacional, assunto do qual a próxima seção se ocupa.

\section{COMPETÊNCIA INTERACIONAL}

A teoria da competência interacional tem suas origens, conforme assinala Young (2000b), na antropologia linguística e seu domínio é a interação face a face. Trata-se de uma teoria que busca explicar as características socioculturais de práticas discursivas e o processo interacional pelo qual essas práticas são coproduzidas pelos falantes.

A noção de discurso como ação - e não meramente como representação do mundo ou expressão do pensamento - é a base das teorizações sobre CI. Quer dizer, ao invés de se concentrar em como as coisas são ou deveriam ser, esta abordagem se interessa em como as práticas sociais e discursivas se dão na interação e em como o significado é estabelecido, negociado, mantido e transformado na interação (YOUNG, 2000a, 2000b). A coprodução, portanto, é um dos fundamentos da teoria da CI. Analisar a interação ou avaliar essa competência implica, assim, considerar o que está sendo realizado pelos falantes em determinado contexto, por meio de práticas sociais e discursivas.

$\mathrm{Na}$ teoria da $\mathrm{CI}$, as "habilidades" orais não existem dentro do cérebro do falante bilíngue, tampouco pertencem ao indivíduo; antes disso, são construídas de modo conjunto pelos falantes engajados na interação. Isso significa dizer que a noção de $\mathrm{CI}$ difere de maneira fundamental do conceito de competência comunicativa, cujo foco é no usuário individual da língua em dado contexto social (JACOBY, OCHS, 1995 apud YOUNG, 2000b). Nesta direção, vale registrar que, segundo McNamara (1997), enquanto Dell Hymes estruturou sua discussão sobre interação como aspecto de uma competência expandida em seu modelo de competência co- 
municativa, Halliday, por outro lado, adotou uma perspectiva exclusivamente social e contextual da interação, concebendo a organização da língua como um recurso compartilhado de significado.

As práticas interacionais - definidas por Hall (1995 apud YOUNG, 2000a) como amostras reais de interação - são episódios recorrentes de fala que têm determinada estrutura e um significado sociocultural particular (YOUNG, 2000a). A construção de uma prática interacional é uma ação conjunta dos interlocutores que fazem uso de recursos interacionais apreendidos em práticas anteriores e recorrem a elementos interacionais para dar corpo à prática. A estrutura dessa prática é formada pelos modos com que esses recursos são explorados e combinados pelos interlocutores conjuntamente (YOUNG, 2000a, p. 36-7).

Para o autor, a competência interacional caracteriza-se pelo uso de certos recursos baseados em conhecimentos sobre: roteiros e argumentos retóricos (ou sequências de atos de fala); ambientes de participação; registro, isto é, de certas estruturas sintáticas, lexicais e relações semânticas específicas para a prática; estratégias de participação para administrar turnos; organização do tópico, que inclui preferências por certos tópicos e decisões sobre quem tem o direito de introduzir determinado tópico, quanto deve durar um tópico e quem tem o direito de mudar o tópico; e maneiras apropriadas de participação da interação, que se referem às diferentes formas de os falantes assumirem papéis e de ratificarem os papéis de seus interlocutores, o que inclui conhecer o significado de sinalizações que demarcam as fronteiras de determinada prática (sua abertura, fechamento e transições dentro da própria prática), entre outros. Em síntese, estudos como os de Young fornecem evidências de elementos específicos que caracterizam a competência interacional e são, portanto, passíveis de observação em uma interação face a face.

Inúmeros estudos revelam de forma contundente, por exemplo, a sensível alteração em aspectos fonológicos, morfológicos e sintáticos específicos do desempenho do falante bilíngue em função de mudanças contextuais, tais como interlocutor, tarefas ou tópico. A título de ilustração, menciono, a seguir, algumas formulações baseadas em pesquisas acerca da interação entre falantes nativos e bilíngues. Antes, porém, cabe pontuar que resultados de pesquisas sobre interação entre falantes nativos e bilíngues não são referências generalizáveis de modelos interacionais de determinada língua, nação ou cultura. Proceder a tais generalizações é, primeiro, ignorar a imensa diversidade linguística, discursiva e pragmática que caracteriza a linguagem, segundo, ignorar o papel crucial que os 
interlocutores, seus propósitos e o contexto têm na interação e, por fim, destituir a linguagem de sua natureza social, histórica, cultural e política.

Isso explica a supressão, neste artigo, de referências à nacionalidade dos falantes (nativos e bilíngues) das pesquisas que descrevo adiante, buscando, por um lado, evitar que princípios essencialistas, estáticos e deterministas da relação entre nação, língua, cultura e identidade (KRAMSCH, 2004) sejam reiterados e, por outro, ser coerente com as perspectivas teóricas adotadas, nas quais identidade, cultura, propósitos dos interlocutores e contexto de interação não são elementos acessórios, estáveis e preexistentes (KRAMSCH, 2004; YOUNG, 2000a), e sim construções discursivas que se dão em um continuum que se inicia antes da interação e se operacionaliza ao longo dela e, por isso, dependem crucialmente da interação para serem descritas. Dito isso, apresento, a seguir, algumas pesquisas sobre interação em LA.

Estudos de Tarone (2007), por exemplo, revelam que o desempenho da pronúncia de falantes bilíngues se altera em resposta a mudanças no interlocutor ou na tarefa; as produções orais e escritas de falantes bilíngues são significativamente mais fluentes e mais precisas em alguns contextos sociais do que em outros. Shea (1994 apud YOUNG, 2000b), por sua vez, assinala que determinados falantes bilíngues se mostram mais proficientes em LA quando o acesso ao piso conversacional é relativamente simétrico e/ou seus posicionamentos a respeito do tópico são congruentes com as de seu interlocutor.

Richard Young (2000a, 2000b) aponta várias pesquisas cujos resultados interessam a esta discussão. Uma delas baseia-se na análise de reuniões de orientação acadêmica entre professores universitários e seus alunos estrangeiros, a partir da qual os pesquisadores que conduziram o estudo constataram que a transferência imprópria de sinalizações de abertura e fechamento de tópicos de uma prática interacional para outra pode resultar em incompreensões tanto na comunicação, quanto nas relações sociais entre os interlocutores. Nas situações em questão, os alunos estrangeiros, cuja primeira língua não era a mesma do professor, encerravam a interação invocando novamente assuntos discutidos durante a reunião. Os estudiosos alertam que esse modelo é totalmente aceitável numa interação informal, indicando que nenhum dos falantes tem outro tópico para introduzir, mas naquele contexto, esse modelo foi responsável por incompreensões de diversas naturezas entre os interlocutores, incluindo estigmas culturais.

Em resumo: a CI é compreendida como uma ação social conjunta entre os falantes, na qual se entende que os interlocutores precisam colaborar uns com 
os outros, dividindo a responsabilidade pelo sequenciamento da conversa, pela tomada de turno, pela organização do tópico, pela sinalização dos papéis que cada interlocutor assume na interação, entre outros. Essa competência volta-se para o uso da linguagem em práticas situadas em um contexto social específico, e não para habilidades linguísticas independentes do contexto. Caracteriza-se pelo foco na construção de práticas discursivas empreendidas por todos os interlocutores envolvidos, ao invés de focalizar um único falante.

\subsection{Interação e avaliação do desempenho oral em LA}

Em encontros de acesso controlado, em que um falante nativo controla o acesso de um falante bilíngue a um fim desejado, como no caso de um exame de proficiência oral em LA, a diferença de estilos conversacionais entre quem avalia e quem se submete à avaliação pode trazer consequências bastante negativas para estes últimos. Pesquisas sobre estas práticas interacionais têm mostrado que falantes bilíngues tendem a transferir estilos conversacionais da primeira língua (L1, daqui em diante) para a LA e, no momento em que os avaliadores classificam esses estilos como impróprios para o contexto, suas percepções acerca do desempenho dos examinandos em outros aspectos de sua produção oral também passam a ser negativas.

Neste sentido, Young (2000a) destaca um estudo comparativo entre examinandos de duas nacionalidades distintas em um exame de proficiência em inglês que ilustra bem essa questão: enquanto falantes asiáticos responderam de forma sucinta às perguntas dos entrevistadores, falantes latino-americanos desenvolveram mais os tópicos. $\mathrm{O}$ estudo revelou que as respostas breves resultaram em pontuações/notas mais baixas em todos os critérios analisados, mesmo que, em termos de vocabulário, pronúncia e estrutura gramatical, esses examinandos apresentassem desempenho semelhante ao daqueles cujas respostas eram mais extensas. Outra pesquisa apontada por Young (2000a) diz respeito a um teste no qual examinandos oriundos de determinado país tiveram seu desempenho na LA classificado como baixo em função de não interagirem conforme o esperado na cultura do entrevistador (falante nativo da língua avaliada), isto é, não valorizando devidamente sua autoridade, fornecendo-lhe mais informações do que o esperado e adotando estilo informal na interação, considerado inadequado àquele interlocutor.

Sakamori (2006) também destaca estudos que, a partir da comparação de diferentes estilos conversacionais em exames para avaliação de produção oral, 
revelam que a cultura e o grau de proficiência na LA dos examinandos incidem na configuração da interação, podendo exigir do entrevistador menos esforço, maior velocidade da fala e maior frequência na mudança de tópicos. Outras pesquisas, segundo Sakamori (2006, p. 56), centradas nos estilos de entrevistadores de diferentes línguas, evidenciam que "a maneira como o entrevistador conduz uma entrevista pode variar segundo o estilo conversacional de uma determinada cultura": enquanto alguns entrevistadores enfatizam a forma e têm um estilo parecido com o de um professor, outros centram sua atenção no conteúdo e dependem da contribuição do examinando para que a interação flua. $\mathrm{O}$ estudo desenvolvido por Sakamori (2006), por sua vez, revelou que a atuação dos entrevistadores na interação face a face do Exame Celpe-Bras varia entre colaborativa e não colaborativa, diferença que pode ser decisiva para o desempenho do examinando.

Partindo, então, do princípio que ações interacionais são respostas aos movimentos dos outros falantes, a teoria da $\mathrm{Cl}$ compreende que a definição de interação deve levar em conta, entre outros aspectos, o grau de suporte do interlocutor. Sob esta ótica, o foco exclusivo na contribuição individual para a interlocução deveria ser problematizado a partir da noção de que os movimentos interacionais dos interlocutores não estão na instância individual. Por isso, compreender a CI como uma competência individual e de natureza exclusivamente cognitiva é um equívoco, conforme criticam Fulcher (2003), Young (2000a, 2000b) e outros. É nesta direção que vários autores, a exemplo de McNamara (1997), enfatizam a necessidade de se colocar em foco aqueles cuja interpretação e ações na interação orientam os esforços do examinando, o que não significa avaliar o entrevistador, mas sim considerar que muitas escolhas interacionais do examinando são respostas às circunstâncias/contexto da entrevista e aos movimentos interacionais do entrevistador.

A partir das discussões empreendidas nesta seção, parece razoável sustentar que, ainda que o construto de língua seja uma questão de argumentação e justificativa, configurando-se uma construção teórica localmente definida e intrinsecamente vinculada ao propósito do exame, conforme assinala Scaramucci (2009, p. 35), um exame que se proponha a avaliar determinada dimensão da linguagem, tal como a CI, não deve prescindir das concepções teóricas correntes propostas por estudos dedicados, de maneira mais ampla, a essa dimensão. 


\title{
3. COMPETÊNCIA INTERACIONAL E A GRADE DE AVALIAÇÃO DA PARTE ORAL DO CELPE-BRAS
}

Os dois avaliadores da Parte Oral do Exame Celpe-Bras utilizam grades de avaliação distintas: enquanto o entrevistador analisa o desempenho do examinando a partir de uma grade holística, o observador ${ }^{5}$ dispõe de uma grade analítica, com gradações de desempenho específicas para os diferentes níveis de proficiência, a saber: Avançado Superior, Avançado, Intermediário Superior, Intermediário, Básico e Sem Certificação. Scaramucci (2009, p. 35), citando McNamara (2000), lembra que

\begin{abstract}
avaliações em geral são baseadas em inferências sobre um determinado critério, visto como o conjunto de comportamentos que se deseja avaliar. Esses comportamentos são subsequentes a um teste e, portanto, não observáveis. A única maneira de torná-los observáveis é caracterizá-los para que possam ser simulados ou representados, sempre de forma amostral, na elaboração do instrumento. Os dados de desempenho observados a partir da aplicação do teste serão usados para fazermos inferências sobre o critério, permitindo observar o que antes não era observável.
\end{abstract}

Luoma (2005) ressalta que a grade deve estar de acordo com a definição de construto do exame e diretamente ligada às tarefas, daí a necessidade de construto, tarefas e critérios serem desenvolvidos juntos. Para ser operacional, a grade precisa descrever de forma breve, clara e compreensível os componentes da produção e da compreensão oral que o tipo de interação proposta no exame pode revelar e discriminá-los em critérios. As descrições de cada critério, por sua vez, devem ser claras, concretas e práticas, não muito longas e nem muito detalhadas. Em relação aos níveis de proficiência, a autora assinala que a grade deve ter definições verbais de cada nível que guiem os avaliadores de forma consistente e relativamente inequívoca. Segundo Luoma (2005, p. 68), as grades analíticas, em geral, disponibilizam orientações práticas do que avaliar, fornecendo informações sobre os "pontos fortes e específicos a serem avaliados no desempenho do examinando".

Disto isto, passo à análise de um dos aspectos adotados na Parte Oral do Exame Celpe-Bras para avaliar o desempenho dos examinandos na CI. Para tanto, apresento, a seguir, a Ficha de Avaliação da interação face a face/observador.

\footnotetext{
5 Registro que não analisei a ficha de avaliação utilizada pelo entrevistador em função de se tratar de uma versão "sumarizada" dos descritores da Ficha de avaliação usada pelo observador, não havendo, portanto, informações adicionais sobre competência interacional que justificassem incorporá-la a esta análise.
} 
Quadro 1. Ficha de avaliação da interação face a face/observador

\begin{tabular}{|c|c|c|c|c|c|c|}
\hline & 5 & 4 & 3 & 2 & 1 & 0 \\
\hline & $\begin{array}{l}\text { Apresenta mui- } \\
\text { ta desenvoltura } \\
\text { e autonomia, } \\
\text { contribuindo } \\
\text { muito para o } \\
\text { desenvolvimen- } \\
\text { to da conversa. }\end{array}$ & $\begin{array}{l}\text { Apresenta de- } \\
\text { senvoltura e au- } \\
\text { tonomia. Não se } \\
\text { limita a respostas } \\
\text { breves, contri- } \\
\text { buindo para o } \\
\text { desenvolvimen- } \\
\text { to da conversa. }\end{array}$ & $\begin{array}{l}\text { Não se limita a } \\
\text { respostas bre- } \\
\text { ves, contribuin- } \\
\text { do para o de- } \\
\text { senvolvimento } \\
\text { da conversa. }\end{array}$ & $\begin{array}{l}\text { Pode se limitar a } \\
\text { respostas breves, } \\
\text { mas contribui } \\
\text { para o desenvol- } \\
\text { vimento da con- } \\
\text { versa. }\end{array}$ & $\begin{array}{l}\text { Limita-se a res- } \\
\text { postas breves, } \\
\text { contribuindo } \\
\text { pouco para o } \\
\text { desenvolvimen- } \\
\text { to da conversa. }\end{array}$ & $\begin{array}{l}\text { Limita-se a res- } \\
\text { postas breves, } \\
\text { raramente con- } \\
\text { tribuindo para o } \\
\text { desenvolvimento } \\
\text { da conversa, que } \\
\text { fica dependente } \\
\text { do avaliador. }\end{array}$ \\
\hline 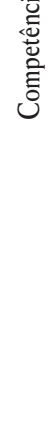 & $\begin{array}{l}\text { Quando neces- } \\
\text { sário, faz uso } \\
\text { de estratégias } \\
\text { (reformulações, } \\
\text { paráfrases, cor- } \\
\text { reções) para } \\
\text { resolver pro- } \\
\text { blemas lexicais, } \\
\text { gramaticais e/ } \\
\text { ou fonológicos. }\end{array}$ & $\begin{array}{l}\text { Quando neces- } \\
\text { sário, faz uso } \\
\text { de estratégias } \\
\text { (reformulações, } \\
\text { paráfrases, cor- } \\
\text { reções) para re- } \\
\text { solver problemas } \\
\text { lexicais, gramati- } \\
\text { cais e/ou fonoló- } \\
\text { gicos. }\end{array}$ & $\begin{array}{l}\text { Quando neces- } \\
\text { sário, faz uso } \\
\text { de estratégias } \\
\text { (reformulações, } \\
\text { paráfrases, cor- } \\
\text { reções) para } \\
\text { resolver pro- } \\
\text { blemas lexicais, } \\
\text { gramaticais e/ou } \\
\text { fonológicos. }\end{array}$ & $\begin{array}{l}\text { Mesmo quan- } \\
\text { do necessário, } \\
\text { faz pouco uso } \\
\text { de estratégias } \\
\text { (reformulações, } \\
\text { paráfrases, cor- } \\
\text { reções) para re- } \\
\text { solver problemas } \\
\text { lexicais, gramati- } \\
\text { cais e/ou fonoló- } \\
\text { gicos. }\end{array}$ & $\begin{array}{l}\text { Mesmo quan- } \\
\text { do necessário, } \\
\text { faz pouco uso } \\
\text { de estratégias } \\
\text { (reformulações, } \\
\text { paráfrases, cor- } \\
\text { reções) para } \\
\text { resolver pro- } \\
\text { blemas lexicais, } \\
\text { gramaticais e/ } \\
\text { ou fonológicos. }\end{array}$ & $\begin{array}{l}\text { Mesmo quando } \\
\text { necessário, não } \\
\text { faz uso de estra- } \\
\text { tégias (reformula- } \\
\text { ções, paráfrases, } \\
\text { correções) para } \\
\text { resolver pro- } \\
\text { blemas lexicais, } \\
\text { gramaticais e/ou } \\
\text { fonológicos. }\end{array}$ \\
\hline
\end{tabular}

Conforme o quadro acima, o desempenho na $\mathrm{CI}$ é avaliado em termos de: (a) desenvoltura e autonomia; (b) contribuição para o desenvolvimento da conversa; (c) uso de respostas breves e (d) uso de estratégias para resolver problemas lexicais, gramaticais e/ou fonológicos. Antes de encaminhar as discussões sobre estratégias comunicativas, aspecto sobre o qual este artigo se debruça, ressalto, primeiro, que o objetivo deste texto não é empreender uma análise exaustiva ou pormenorizada do tema; antes disso, o artigo busca apenas levantar algumas questões sobre o emprego dessas estratégias enquanto aspecto da CI. Segundo, os outros aspectos previstos pela grade para a avaliação dessa competência - desenvoltura e autonomia, uso de respostas breves e contribuição para o desenvolvimento da conversa - não são abordados neste artigo em função da carência de definições formuladas no interior de áreas de estudos voltadas à interação face a face, que embasem teoricamente a discussão, e de pesquisas que apontem evidências de que tais aspectos são elementos da $\mathrm{Cl}$ ou a caracterizam. Isto significa dizer que a discussão sobre desenvoltura, autonomia, uso de respostas breves e contribuição para o desenvolvimento da conversa se limitaria 
à análise semântica das descrições em si, desviando-se do foco sob o qual discuto estratégias comunicativas.

\subsection{Uso de estratégias comunicativas}

Estratégias comunicativas, segundo Ellis (2000), podem ser vistas como a capacidade de resolver problemas na linguagem, mas também como capacidade cognitiva de gerenciar a interação. Em que pese a Ficha de Avaliação (cf. Quadro 1) não utilize o termo "estratégia comunicativa", os exemplos disponibilizados ao avaliador - reformulação, paráfrase, correções -, e a função de seu uso, também explicitada nessa Ficha - resolver problemas lexicais, gramaticais e/ou fonológicos - deixam claro que se trata de estratégias comunicativas (EC, daqui em diante) enquanto recursos para resolver problemas na linguagem, e não da capacidade cognitiva de gerenciamento da interação. Soma-se a isso o fato de a versão eletrônica simplificada do Guia do Examinando (2013, p. 11) empregar especificamente o termo estratégia comunicativa ao informar que o uso de recursos interacionais e estratégicos é um dos aspectos contemplados na grade de avaliação da Parte Oral do Exame, caracterizando-os da seguinte maneira: "contribuição para o desenvolvimento da conversa, flexibilidade na mudança de tópico, uso de estratégias comunicativas, adequação ao interlocutor. [...]" (é meu o grifo em negrito).

O tema é envolto em polêmicas e desencontros. Para Dörnyei e Scott (1997) e Ellis (2000), a discordância que tem caracterizado os estudos sobre EC se deve tanto à diversidade de perspectivas teóricas e concepções de língua dos pesquisadores que tratam do tema, quanto à falta de clareza sobre a linguagem estratégica. Na citação a seguir, Dörnyei e Scott (1997, p. 181-2) sintetizam os principais estudos dedicados às ECs:

Faerch e Kasper (1983b) concebem as EC como planos verbais dentro de um quadro de produção da fala; Tarone (1980) as compreende a partir de uma perspectiva analítica do discurso e segue uma abordagem interacional, Dörnyei (1995) ampliou o âmbito da sua definição para incluir recursos que não eram relacionados estritamente ao significado; Dörnyei e Scott (1995a, 1995b) compararam o uso da linguagem estratégica ao comportamento de resolução de problemas de comunicação em geral; Canale (1983) propôs também a inclusão de estratégias de não resolução de problemas; Bialystok (1990) e o Grupo de Nijmegen consideraram as ECs como eventos essencialmente mentais e adotaram uma abordagem cognitivo-psicológica para sua análise e; finalmente Poulisse (1993, no prelo-b) desenvolveu a perspectiva psicolinguística, integrando ECs a uma versão adaptada do quadro de produção de fala proposto por Levelt (1989). 
Ainda que não haja consenso a respeito da definição, categorização e perspectiva teórica a partir da qual as ECs devem ser investigadas, essas estratégias têm sido compreendidas, de forma geral, como recursos verbais ou não verbais que falantes bilíngues conscientemente lançam mão para superar impasses linguísticos e/ou pragmáticos decorrentes de variáveis em seu desempenho oral em LA. Quer dizer, a orientação para a resolução de problemas e a consciência em seu uso são critérios de definição que permeiam boa parte dos estudos dedicados às ECs, independentemente da perspectiva teórica a que estejam atrelados. Outro consenso entre os pesquisadores é a seguinte formulação de Ellen Bialystok (1990): "as estratégias comunicativas são um evento inegável de uso da linguagem, a sua existência é um aspecto da comunicação documentado de forma confiável, e seu papel na comunicação em língua adicional parece particularmente relevante".

De acordo com Ellis (2000), pesquisas baseadas em taxonomias buscam não só descrever as ECs usadas por diferentes falantes bilíngues, mas também identificar fatores que influenciam a escolha dessas estratégias, tais como: nível de proficiência em LA, personalidade, situação e natureza da tarefa. A taxonomia proposta por Dörnyei e Scott (1997), que é uma entre várias, abrange 33 estratégias comunicativas, entre as quais estão a reformulação, a paráfrase e a [auto]correção, estratégias apontadas na Ficha de avaliação da interação face a face do Celpe-Bras. Os autores assinalam que a descrição de uma estratégia requer que se observe o tipo de problema e o tipo de solução adotada.

Faz-se necessário registrar que taxonomias como essa têm sido alvo de críticas. Bialystok (1990) e Kellerman (1991), citados por Ellis (2000), por exemplo, tecem críticas à imprecisão, arbitrariedade e irrelevância que, muitas vezes, caracterizam os critérios para a determinação de uma categoria de estratégia específica, impossibilidade de generalização dessas taxonomias por meio de tarefas e implausibilidade dessas taxonomias em termos psicológicos. Esses autores defendem que a classificação de EC é uma ilusão, haja em vista que realizações linguísticas diferentes, ainda que reflitam o mesmo processo cognitivo básico, são classificadas como ECs distintas. Isso talvez explique o número reduzido de exames que incluem as ECs em suas grades, segundo Fulcher (2003). Outra crítica às ECs diz respeito à tendência em criar mais e mais taxonomias, ampliando-as, subdividindo-as de maneira interminável, tornando-as, portanto, cada vez menos operacionais. Ainda que essas críticas sejam pertinentes, é preciso reconhecer que a inserção do uso de EC em uma grade de avaliação de proficiência oral requer o estabelecimento de categorias específicas dos recursos que devem ser observados no desempenho do 
examinando, bem como evidências que permitam identificar o uso desses recursos. É aí que as taxonomias existentes na literatura executam papel importante.

Com o objetivo de investigar a relação entre EC e nível de proficiência, Santos e Niederauer (2004) analisaram 20 entrevistas orais de alunos de um programa de ensino e pesquisa em português para estrangeiros. A pesquisa analisou o uso de EC a partir da variável nivel de proficiência em português, comparando as provas orais de 05 alunos de cada um dos seguintes níveis: Avançado II, Avançado I, Intermediário $^{6}$ e Iniciante $\mathrm{II}^{7}$. As entrevistas orais, todas registradas em vídeo, consistiam em interações de 20 minutos entre um aluno e dois avaliadores, nos mesmos moldes da Parte Oral do Exame Celpe-Bras, e objetivavam avaliar a aprendizagem dos alunos nos cursos que acabavam de frequentar. Para a análise e classificação das ECs, optou-se pela taxonomia de Dörnyei e Scott (1997) em função de sua abrangência e da clareza na definição das estratégias. O quadro a seguir apresenta a relação entre as estratégias comunicativas ${ }^{8}$ empregadas pelos alunos nessa entrevista e seu nível de proficiência, que corresponde ao curso de português que cada um frequentara ao longo do bimestre.

Quadro 2. Relação - EC X Nível de proficiência em português

\begin{tabular}{|c|l|l|l|l|l|}
\hline & Avançado II & Avançado I & Intermediário & Iniciante II \\
\hline 1. Autocorreção & & & & \\
\hline 2. Aproximação & & & & \\
\hline $3 . \quad$ Reestruturação & & & & \\
\hline $4 . \quad$ Enchimento & & & & \\
\hline 5. Autorrepetição & & & & \\
\hline 6. Paráfrase & & & & \\
\hline $7 . \quad$ Palavra geral & & & & \\
\hline 8. Redução da & & & & \\
\hline mensagem & Palavra cunhada & & & & \\
\hline
\end{tabular}

6 À época da implementação da pesquisa, o Programa oferecia apenas um nível Intermediário, sem a tradicional subdivisão I e II, o que justifica sua ausência nesta tabela.

7 Os alunos do Iniciante II tinham aulas de português há pouco mais de 04 meses e, por isso, seu domínio da língua era bastante elementar, nível que equivaleria ao Básico ou ao Sem Certificação do Exame Celpe-Bras.

8 Reitero que, apesar da taxonomia adotada listar 33 ECs, constam do Quadro 2 apenas as ECs empregadas pelos alunos ao longo da entrevista. 


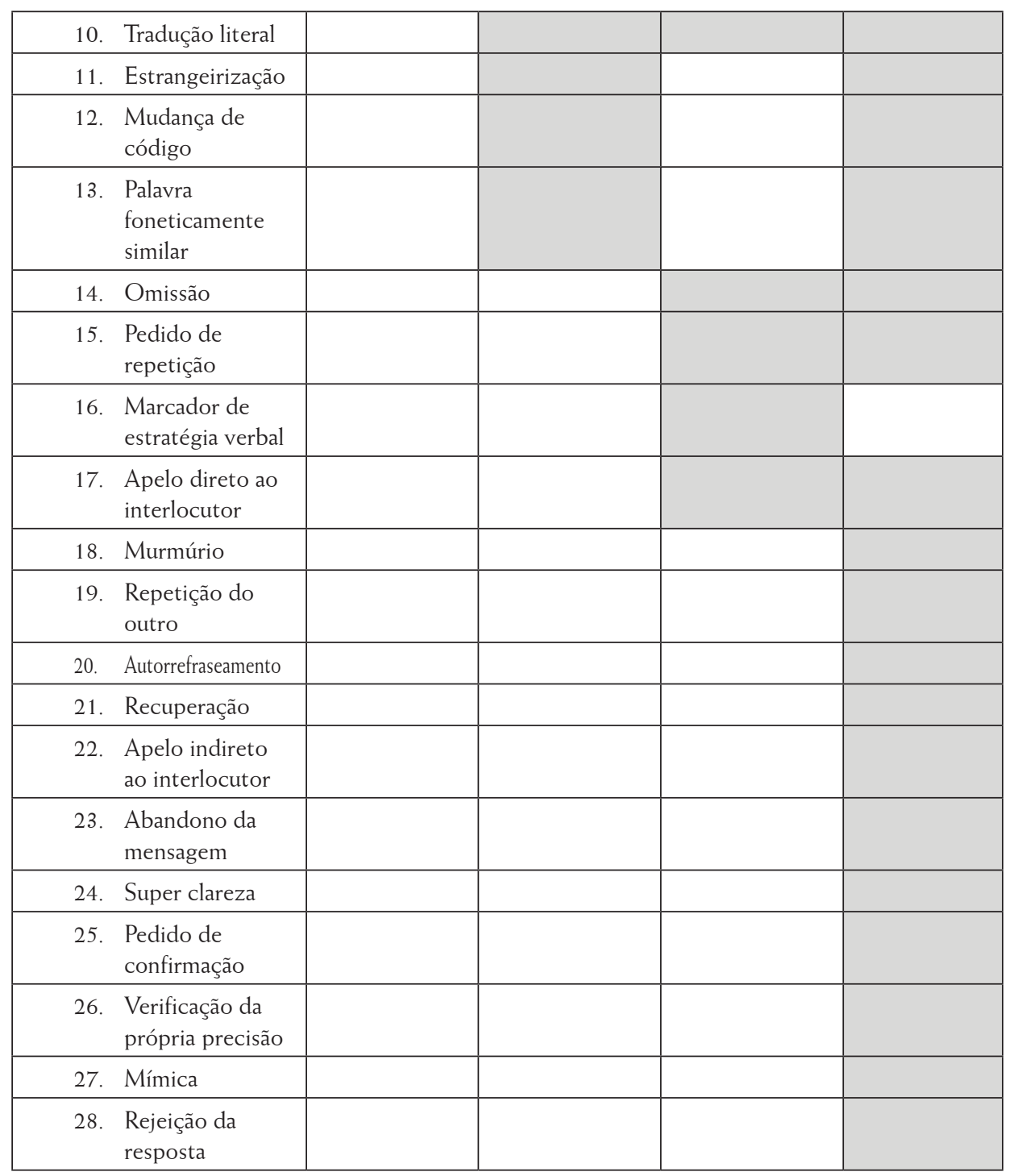

A análise dos dados (cf. Quadro 2) revelou que as ECs a que os alunos de nível avançado recorreram foram usadas também por alunos dos outros níveis, e que quanto menor a proficiência, maior a diversidade de estratégias que os examinandos lançam mão durante a interação. Ou seja, o que caracteriza o nível de proficiência em LA não é o uso de ECs, mas sim "o não uso" de determinadas ECs, tais como: mímica, murmúrio, abandono da mensagem e apelo ao interlocutor (entrevistador). As ECs usadas pelos alunos do nível Avançado II poderiam ser chamadas de ECs básicas, tendo em 
vista que seu uso pareceu independer do nível de proficiência oral do examinando. Destaco ainda que a autocorreção se revelou a EC mais usada pelos alunos, o que possivelmente se explique pela situação em que a coleta de dados se deu: avaliação de proficiência oral.

A partir da análise, ficou claro também que, quanto maior o nível de proficiência do aluno, menor foi a necessidade de apelo a EC. Esse resultado de forma alguma surpreende; afinal, se as ECs são recursos verbais ou não verbais a que falantes bilíngues recorrem para superar problemas de ordem lexical, gramatical e/ou fonológica durante a interação, pela lógica, quanto maior o nível de proficiência do falante, menos problemas terá na comunicação e, portanto, menor será a necessidade de uso de EC. De acordo com a Ficha de Avaliação da interação face a face do Exame Celpe-Bras, porém, nos níveis Intermediário e Básico, o avaliador deve esperar que o examinando faça pouco uso de EC, mesmo quando necessário, e que não faça uso desses recursos no Sem Certificação. Outra inconsistência na descrição deste aspecto é, então, pressupor que um falante bilíngue em contexto de avaliação, diante de um impasse na comunicação, pode não usar esse tipo de recurso, quando, em geral, ele tenderá a lançar mão de uma ampla gama de recursos, que vão desde aqueles linguisticamente mais elaborados, usados nos níveis mais altos, como paráfrase, reformulação e autocorreção, até aqueles que evidenciam sua baixa proficiência, tais como abandono da mensagem, omissão e mímica.

Dizer quando necessário, faz uso de estratégias não equivale, acredito, a esclarecer que os níveis mais altos de proficiência apresentarão menos problemas lexicais, gramaticais e/ou fonológicos; tampouco desfaz a orientação equivocada acerca dos níveis mais baixos de proficiência, a partir da qual o avaliador é levado a considerar que examinandos cuja proficiência oral é menor não fazem uso de EC.

Cabe pontuar que não só os falantes bilíngues recorrem a EC, em busca de compreensão mútua, mas falantes nativos também se valem desses recursos interacionais à medida que possíveis impasses se apresentam na interação com um bilíngue ou mesmo com outro falante nativo. Estudos como os de Tsui (1995) revelam que determinadas estratégias são utilizadas preferencialmente por falantes nativos e outras, por bilíngues. Por exemplo, a verificação de compreensão em geral é usada por falantes nativos, enquanto que o pedido de repetição, pelos falantes bilíngues. No âmbito da sala de aula de LA, a verificação da compreensão e a autorrepetição são dois dos principais recursos adotados pelos professores para facilitar a compreensão oral dos alunos, enquanto que o pedido de confirmaçãa, o pedido de esclarecimento e o pedido de repetição são artifícios usados para entender os enunciados de seus alunos (TSUI, 1995). ECs como a verificação da compreensão, portanto, podem ser muito produtivas para sondar 
se o examinando não respondeu à questão do entrevistador porque não entendeu a pergunta ou porque não domina o tópico proposto. Lynch (1996) afirma ainda que a repetição e a reformulação do que já foi dito tendem a ser mais frequentes em sala de aula de iniciantes.

Levando em conta que o nível de proficiência do falante bilíngue tem implicações tanto para as ECs que usa, quanto pelas usadas pelo interlocutor (falante nativo), o tipo de EC, a variedade e a frequência com que são empreendidas na interação para avaliação da produção e compreensão oral em LA podem ser indícios bastante claros, práticos e concretos do nível de proficiência oral do examinando.

Considerando a variedade de ECs, as diferentes funções que cada uma cumpre na interação e o potencial que têm para indicar o nível de proficiência em LA, parece-me razoável dizer que a forma como essas estratégias são operacionalizadas na Ficha de avaliação da interação face a face do Celpe-Bras não permite que se aproveite a capacidade avaliativa que oferecem.

Vale ressaltar que não há dúvidas de que a formação adequada dos avaliadores permite a compreensão e a aplicação esperadas de todos os critérios propostos em uma grade de avaliação. Essa formação, cujas implicações para a confiabilidade do Exame são óbvias, não é, entretanto, o foco deste artigo, que se limitou a analisar as orientações para a avaliação da CI fornecidas pela grade de avaliação da interação face a face, por um dos manuais que dá suporte aos avaliadores e pelo Guia do Examinando. Apenas a título de complementação, acrescento uma citação de Furtoso (2011, p. 208) na qual sugere que, na avaliação, mais do que no ensino de LA, observa-se que os professores reproduzem práticas vivenciadas durante seus anos escolares, o que, segundo a autora, pode ser explicado "pela falta de espaço, nos cursos de graduação, para uma formação aprofundada em avaliação".

Numa tentativa de operacionalizar as discussões empreendidas ao longo do artigo na Ficha de avaliação da interação face a face do Exame Celpe-Bras, apresento, a seguir, uma proposta para a avaliação do uso de ECs, na qual busco explicitar, em algum detalhe ${ }^{9}$, a noção de EC e seu uso em avaliações de produção e compreensão orais. Por não ter apresentado qualquer evidência concreta sobre desenvoltura e autonomia, tampouco sobre respostas breves e contribuição para o desenvolvimento da conversa, a proposta a seguir mantém a descrição desses aspectos conforme a Ficha analisada.

\footnotetext{
9 Trata-se de uma proposta absolutamente embrionária, sujeita, portanto, a reformulações de várias ordens.
} 
Quadro 3. Sugestão de descrições para a avaliação de EC

\begin{tabular}{|c|c|c|c|c|c|c|}
\hline & 5 & 4 & 3 & 2 & 1 & 0 \\
\hline 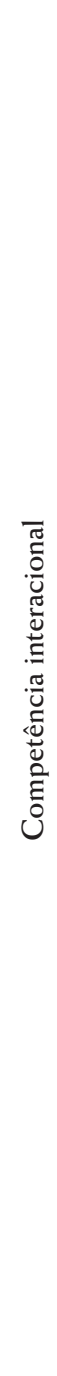 & $\begin{array}{l}\text { Rara neces- } \\
\text { sidade de } \\
\text { uso de EC. } \\
\text { Para superar } \\
\text { eventuais } \\
\text { problemas } \\
\text { l ex i c a is, } \\
\text { gramaticais } \\
\text { e/ou fo- } \\
\text { nológicos, } \\
\text { lança mão } \\
\text { de recursos } \\
\text { ling u isti - } \\
\text { c a m e n t e } \\
\text { elaborados } \\
\text { (reformu- } \\
\text { lação, pará- } \\
\text { frase e au- } \\
\text { tocorreção). } \\
\text { Raramente } \\
\text { deixa de } \\
\text { usar a língua } \\
\text { portuguesa. }\end{array}$ & $\begin{array}{l}\text { Pouca ne- } \\
\text { cessidade de } \\
\text { uso de EC. } \\
\text { Para superar } \\
\text { proble mas } \\
\text { lexicais, gra- } \\
\text { maticais e/ou } \\
\text { fonológicos, } \\
\text { lança mão } \\
\text { de recursos } \\
\text { linguistica- } \\
\text { mente ela- } \\
\text { borados, po- } \\
\text { dendo criar } \\
\text { palavras e/ou } \\
\text { expressões a } \\
\text { partir de ou- } \\
\text { tras línguas } \\
\text { (estrangei- } \\
\text { rização, tra- } \\
\text { dução literal } \\
\text { etc.) }\end{array}$ & $\begin{array}{l}\text { Necessidade } \\
\text { de uso de EC. } \\
\text { Para superar } \\
\text { proble mas } \\
\text { lexicais, gra- } \\
\text { maticais e/ou } \\
\text { fonológicos, } \\
\text { lança mão de } \\
\text { variada gama } \\
\text { de recursos. } \\
\text { Pode pedir } \\
\text { ajuda ao inter- } \\
\text { locutor. }\end{array}$ & $\begin{array}{l}\text { Necessidade } \\
\text { de uso de EC. } \\
\text { Para superar } \\
\text { proble mas } \\
\text { lexicais, gra- } \\
\text { maticais e/ou } \\
\text { fonológicos, } \\
\text { lança mão de } \\
\text { variada gama } \\
\text { de recursos. } \\
\text { Pode pedir } \\
\text { ajuda ao in- } \\
\text { terlocutor e } \\
\text { apelar para } \\
\text { murmúrios ou } \\
\text { omissões. }\end{array}$ & $\begin{array}{l}\text { Necessidade } \\
\text { frequente de } \\
\text { uso de EC. } \\
\text { Para superar } \\
\text { proble mas } \\
\text { lexicais, gra- } \\
\text { maticais e/ou } \\
\text { fonológicos, } \\
\text { lança mão } \\
\text { de grande } \\
\text { variedade } \\
\text { de recursos. } \\
\text { Pode pedir } \\
\text { ajuda do in- } \\
\text { terlocutor, } \\
\text { abandonar a } \\
\text { mensagem } \\
\text { e eventual- } \\
\text { mente usar } \\
\text { mímica. }\end{array}$ & $\begin{array}{l}\text { Limita-se } \\
\text { a respos- } \\
\text { tas breves, } \\
\text { raramente } \\
\text { contribuin- } \\
\text { do para o } \\
\text { desenvol- } \\
\text { vimento da } \\
\text { conversa, } \\
\text { que fica de- } \\
\text { pendente do } \\
\text { avaliador. } \\
\text { Necessidade } \\
\text { muito fre- } \\
\text { quente de } \\
\text { uso de EC. } \\
\text { Para superar } \\
\text { problemas } \\
\text { lexic a is, } \\
\text { gramaticais } \\
\text { e/ou fo- } \\
\text { nológicos, } \\
\text { lança mão } \\
\text { de grande } \\
\text { vari edade } \\
\text { de recursos. } \\
\text { Pode pedir } \\
\text { ajuda do in- } \\
\text { terlocutor, } \\
\text { abandonar a } \\
\text { mensagem } \\
\text { ou usar mí- } \\
\text { mica. }\end{array}$ \\
\hline
\end{tabular}

Não há dúvidas de que seria inviável listar todas as ECs elencadas em uma taxonomia como a de Dörnyei e Scott (1997), na Ficha de avaliação, mas acredito que seria produtivo disponibilizá-las no Manual do Aplicador. 


\section{ALGUMAS CONSIDERAÇÕES}

O foco na interação contribuiu de forma decisiva para transformar o campo de ensino de línguas. Em vez do foco explícito na língua, passou-se a enfatizar o falante bilíngue interagindo com outros falantes, negociando e criando significados, agindo no mundo por meio da língua. Perspectiva que possibilitou novos olhares sobre a avaliação de desempenho oral em LA. A incorporação da própria $\mathrm{CI}$ a grades de avaliação de exames revela esta reorientação dos instrumentos de avaliação da produção oral em LA. Sem dúvidas, contemplar essa competência na grade de avaliação de um exame é um passo importante em direção às concepções contemporâneas de linguagem e interação. Mas, para alinhar-se de fato a tais concepções, é crucial que o exame tenha claro - e esclareça - como pretende avaliar $\mathrm{CI}$.

É incontestável a relevância do critério $\mathrm{CI}$ em relação ao construto no qual o Exame Celpe-Bras se alicerça: uso da linguagem como ação no mundo. É inquestionável também a natureza plural, transitória e descontínua da interação face a face, das práticas interacionais e, consequentemente, da CI. Mas, uma vez incluída na grade de avaliação do desempenho oral de um exame de proficiência, essa competência precisa ser definida de maneira clara, concreta e operacional. Isso não significa que a complexidade e a vivacidade da interação face a face e da CI devam ser mutiladas, reduzidas a um script totalmente previsível e desvinculado da ação conjunta dos interlocutores e seus propósitos.

Daí a necessidade de se buscar, por um lado, embasamento nas diversas áreas que teorizam sobre interação face a face e, por outro, gerar evidências e conhecimentos sobre a arquitetura interacional da entrevista e sobre a configuração dos recursos aí mobilizados que justifiquem, de maneira consistente, a implementação da CI como critério de avaliação da produção oral em LA e que ofereçam condições operacionais para aferi-lo. Neste sentido, os dados do próprio Exame Celpe-Bras devem servir de subsídios para um melhor entendimento dessas questões; afinal, esperar que todas as dimensões da produção oral estejam absolutamente mapeadas e claramente definidas para, só então, incluí-las em uma grade de avaliação equivaleria a impedir a natureza vanguardista do Exame.

Por fim, acrescento que, sob a perspectiva de que a realidade, ou melhor, aquilo que é assumido como realidade é fruto de construções discursivas (SILVA, 2006), é razoável considerar que não só o exame tem implicações para o posicionamento e atuação de avaliadores e examinandos, como os avaliadores e examinandos têm implicações, de diversas ordens, para os exames. Trata-se, então, de compreender examinando, avaliador e exame como mutuamente constituídos e discursi- 
vamente construídos. Quer dizer, são práticas sociais e discursivas construídas em conjunto pelo entrevistador e pelo examinando, nas quais os interlocutores - e, consequentemente, a avaliação - se constituem mutuamente. Não restam dúvidas dos desafios que essa nova configuração lança a todos os envolvidos - direta ou indiretamente - em um exame como o Celpe-Bras, até porque, trata-se de um exame que tem servido de referência para a formulação de outros.

\section{REFERÊNCIAS BIBLIOGRÁFICAS}

BRASIL. (2006). Manual do Aplicador do Exame Celpe-Bras. Brasília, Secretaria de Educação Superior (Sesu), Ministério da Educação (MEC).

BRASIL. (2013). Guia do Examinando - Versão Eletrônica Simplificada - Celpe-Bras. Brasília, Instituto Nacional de Estudos e Pesquisas Educacionais Anísio Teixeira (Inep), Ministério da Educação (MEC). Disponível em:http://download.inep.gov.br/outras_acoes/celpe bras/manual/2012/manual_examinando_celpebras.pdf Acesso em: 9 set. 2013.

BROWN, A, (2003). Interviewer variation and the co-construction of speaking proficiency. Language Testing, v. 20, n 1 , pp. 1-25.

CHAPELLE, C. A. (1999). Validity in language assessment. Annual Review of Applied Linguistics, v.19, pp. 254-272.

DÖRNYEI, Z.; SCOTT, M. L. (1997).Communication strategies in a second language: definitions and taxonomies. Language learning. pp. 173-210, mar.

ELLIS, R. (2000). The study of second language acquisition. 17 ${ }^{\mathrm{a}} \mathrm{imp}$. Oxford University Press.

FULCHER, G. (2003). Testing second language speaking. London: Longman.

FURTOSO, V. B. (2011). Avaliação de proficiência em português para falantes de outras línguas: relação com ensino e aprendizagem. In: MENDES, E. (Org.) Diálogos interculturais: ensino e formação em português língua estrangeira. Campinas. pp. 207-236.

KRAMSCH, C. (2004). Language, thought, and culture. In: DAVIS, A. e ELDER, C. (Edits.) The bandbook of Applied Linguistics. Blackwell Publishing. pp. 235-261.

LUOMA, S. (2005).Assessing speaking. Cambridge: Cambridge University Press.

LYNCH, T. (1996). Communication in the language classroom. London: Oxford University Press.

MAHER, T. M. (2007). Do casulo ao movimento: a suspensão das certezas na educação bilíngüe e intercultural. In: Cavalcanti, M. C.; Bortoni-Ricardo, S. M. (orgs.). Transculturalidade, linguagem e educação. 67-94. Campinas, SP: Mercado de Letras.

MCNAMARA, T. F. (1997). 'Interaction' in second language performance assessment: whose performance? Applied Linguistics, v. 18, $\mathrm{n}^{\circ}$ 4, pp. 446-466, dec.

MCNAMARA, T. F.; ROEVER, C. (2006). Language testing: the social dimensions. International Journal of Applied Linguistics, v. 16, $\mathrm{n}^{\circ}$ 2, pp. 242-258. 
SAKAMORI, L. (2006). A atuação do entrevistador na interação face a face do exame Celpe-Bras. Campinas. 190 p. Dissertação (Mestrado em Linguística Aplicada). Instituto de Estudos da Linguagem, Universidade de Campinas.

SANTOS, P. C.; NIEDERAUER, M.(2004). Estratégias comunicativas de falantes de português como L2 em interações não-espontâneas. In: $1^{\circ}$ Encontro de português língua estrangeira do Rio de Janeiro, 2004, Rio de Janeiro, Anais do $1^{\circ}$ Encontro de português língua estrangeira do RJ, Rio de Janeiro: PUC-RJ.

SCARAMUCCI, M. V. R. (2000). Proficiência em LE: considerações terminológicas e conceituais. Trabalbos de Linguística Aplicada, n³ 36, pp.11-22.

SCARAMUCCI, M. V. R. (2009). Avaliação da leitura em inglês como língua estrangeira e validade de construto. Calidoscópio. São Leopoldo/RS. v. 7, nº 1, pp. 30-48, jan./ abr. Disponível em: http://www.unisinos.br/publicacoes_cientificas/images/stories/ pdfs_calidoscopio/Vol7n1/art04_scaramucci.pdf Acesso em: 20 de ago. 2011.

SILVA, T. T. (2006). O currículo como fetiche: a poética e política do texto curricular. $3^{\text {a }}$ reimp. Belo Horizonte, MG: Autêntica.

TARONE, E, (2007). Sociolinguistic approaches to second language acquisition: research - 1997-2007. The modern language journal, v. 91, pp. 837-848.

TSUI, A. B. M. (1995). Classroom interaction. London: Penguin.

YOUNG, R. (2000a) Sociolinguística de la adquisición de segundas lenguas. In: PRESTON, D. R.; YOUNG, R. Adquisición de segundas lenguas: variación y contexto social.Tradução Francisco Moreno Fernández. Madri, Espanha: Arco Libros, pp. 17-38.

YOUNG, R. (2000b). Interactional competence: challenges for validity. Trabalho apresentado no Encontro Anual da American Association for Applied Linguistcs e Language Testing Researcb Colloquium, Vancouver, BC, Canadá, mar., pp. 1-15.

Recebido: 01/08/2014

Aceito::28/11/2014 